phenytoin. Due to ongoing seizure activity was loaded with IV levetiracetam. Did not respond to pyridoxine challenge.

Investigations included bloods and CSF sent for metabolic work up, Serum glycine was 1905 ,with raised CSF:plasma glycine levels EEG (showed burst suppressive pattern) MRInormal.

Child transferred to tertiary centre for ongoing management. Needed 7 days of intensive care, managed by metabolic and neurology teams. Regular follow-up at local centre.

Is currently on phenobarbitone, levetiracetam ,sodium benzoate and folinic acid

Conclusion To date, no effective treatment exists for $\mathrm{NKH}$. The standard treatment strategies for $\mathrm{NKH}$ include sodium benzoate (to reduce plasma concentration of glycine) and NMDA receptor antagonists (ketamine, dextromethorphan, felbamate, and topiramate). Both sodium benzoate and dextromethorphan may improve alertness and decrease seizure frequency if prescribed during the newborn period.

\section{P102 AN ADOLESCENT GIRL WITH ULCUS VULVAE ACUTUM}

Esra Çakmak Taşkın, Halil Özdemir, Kübra Konca, Gül Arga, Ergin Çiftçi, Erdal İnce. Ankara University Faculty of Medicine, Ankara, Turkey

\subsection{6/archdischild-2019-epa.457}

Background Ulcus vulvae acutum (UVA) is a disease characterized by primary aphthous ulcer or reactive nonsexually related acute genital ulcer. The etiology is unknown. The diagnosis is made by excluding other infectious and noninfectious causes which can be responsible for vulvar ulcer.

Case report A 12-year-old girl had a pustule-like lesion which appeared on her genital region 4 days ago and grew rapidly with a swelling and tenderness. Before the admission, she did not take any medication except the analgesics. On the physical examination, no pathological findings were observed other than a very painful ulcero-necrotic lesion with purulent discharge which was on the entrance of the vagina, at 6 o'clock position. The whole blood count showeda hemoglobin level of $12.6 \mathrm{~g} / \mathrm{dL}$, a white blood count of $4210 / \mathrm{mm}^{3}$, and a platelet count of $187000 / \mathrm{mm}^{3}$. ESH was $14 \mathrm{~mm} / \mathrm{h}$ and CRP was $26 \mathrm{mg} / \mathrm{L}$. The serum biochemistry analysis and complete urinalysis were normal. Discharge culture was performed and intravenous piperacillin-tazobactam and fluconazole were administered empirically. Beside the antimicrobial agents oral paracetamol, ibuprofen and topical lidocainewere added to the treatment.Uveitis was not observed andPathergy test and HLA B51 were negative. The vaginal and urine cultures were negative. The serological tests for EBV, CMV, herpes simplex virus (HSV) type 1 and 2, Toxoplasma gondii, parvovirus B19, hepatitis B virus (HBV), hepatitis C virus (HCV), hepatitis A virus (HAV), human immunodeficiency virus (HIV), and VDRL were found to be negative. The patient was started on intravenous methylprednisolone $(2 \mathrm{mg} /$ $\mathrm{kg}$ /day) with the preliminary diagnosis of UVA. Application of topical steroid and anesthetic on the lesions was continued. After the methylprednisolone treatment, the ulcer rapidly shrank and the pain markedly relieved. On the $6^{\text {th }}$ day of hospitalization, the dosage of methylprednisolone was reduced to $1 \mathrm{mg} / \mathrm{kg} /$ day and she was discharged. No new lesions were evident in the follow-up and the methylprednisolone was stopped gradually within 3 weeks. During the 9month follow-up, there were no new lesions and complaints.
Conclusion The most prevalent cause of genital ulcers is HSV and it is related to sexual activity. When vulvar ulcer is observed in children, the history of sexual activity and sexual abuse should be carefully questioned. If there is no history of sexual activity, after excluding all the other possible causes, UVA should be considered first for the differential diagnosis.

\section{P103 IMPROVEMENT ON PERSISTENT VOMITING AFTER ADMINISTRATION OF AMITRIPTYLINE: CASE REPORT FROM LIMITED RESOURCES SETTING IN EAST NUSA TENGGARA, INDONESIA}

Angela Grace*. St Rafael General Hospital, Cancar, Manggarai Regency, Indonesia

\subsection{6/archdischild-2019-epa.458}

Background Cyclic vomiting syndrome (CVS) is a functional gastrointestinal disorder (FGID), characterised by recurring episodes of intense vomiting accompanied by nausea and headache followed by asymptomatic period between the episodes. It remains recognised despite its known prevalence, which is $1.9 \%$ in school-age children worldwide. In Indonesia, neither the prevalence nor the incidence of cyclic vomiting syndrome has been reported. A number of published studies reported that CVS is more common among Caucasians, which explains its obscurity in our country. The lack of awareness of this disorder along with low-resource setting highlights the challenge of this case.

Case presentation This is a case report of paediatric cyclic vomiting syndrome in a local, limited resource private hospital in Manggarai Regency, East Nusa Tenggara, Indonesia. A 10 year-old girl was admitted due to her sixth episode of vomiting over the past six weeks. She was hospitalised a few times due to her episodes of vomiting and was diagnosed with gastro-oesophageal reflux disease (GORD) earlier. Her episodes were characterised by vomiting every 30-60 minutes at first, gradually declining over 3-4 days, and recurring in about 6-7 days. All the available tests results were unremarkable. The diagnosis was established based on the criteria of The International Classification of Headache Disorder 2004 (ICHD-II), excluding possible aetiologies using the only available resources in our location, and resolution of symptoms after administration of amitriptyline. She was discharged with continuous amitriptyline for 2 weeks and went into remission.

Conclusion CVS should always be considered in repeated vomiting in children. When recurrent vomiting is suspected as CVS in limited resources settings, diagnostic therapy should immediately be performed. Recognition of this disorder is important to establish prompt diagnosis and convenient intervention, thus improving the quality of life of the children.

\section{P104 A 9-WEEK BABY WITH PH OF 7.62 AND BICARBONATE OF 66.6}

${ }^{1}$ Phani Bhushan Sanneerappa*, ${ }^{2}$ Bazlin Ramly, ${ }^{2}$ Mathew Thomas,

${ }^{2}$ Moosakutty Chetiyarama. 'Our Lady's Hospital for sick children, Dublin, Ireland; ${ }^{2}$ Letterkenny University Hospital, Letterkenny, Ireland

\subsection{6/archdischild-2019-epa.459}

Introduction Infantile hypertrophic pyloric stenosis (HPS) is a condition where hypertrophy of the pyloric sphincter results in narrowing of the pyloric canal. It is the most common 